\title{
A CRITICAL APPRAISAL OF PACKAGE INSERTS IN INDIA
}

\author{
Makbool Ali M. Agharia1, Ujwala P. Gawali², Harshad V. Kesari³, Kalpana U. Shah ${ }^{4}$ \\ 1 Junior Resident, Department of Pharmacology, Dr. V. M. Government Medical College, Solapur. \\ ${ }^{2}$ Associate Professor, Department of Pharmacology, Dr. V. M. Government Medical College, Solapur. \\ $3 J u n i o r$ Resident, Department of Pharmacology, Dr. V. M. Government Medical College, Solapur. \\ 4 Professor and Head, Department of Pharmacology, Dr. V. M. Government Medical College, Solapur.
}

\begin{abstract}
Accurate and reliable drug information is essential for safe and effective use of marketed products. The primary source of drug information is a Package Insert. It is a printed leaflet that contains information based on regulatory guidelines for the safe and effective use of a drug. Incomplete and incorrect product information may have serious consequences including disability or death. In India, the concept of package insert is governed by the Drugs and Cosmetics Act (1940) and Rules (1945). Keeping this in mind, this study was designed to assess the presentation and completeness of drug information provided in the currently available package inserts for allopathic drugs in India.
\end{abstract}

AIM

To evaluate the presentation and completeness of drug information provided in the currently available package inserts for allopathic drugs in India.

\section{OBJECTIVES}

To evaluate drug information in package inserts according to headings mentioned in Section 6.2 and 6.3 of Schedule D, Drugs and Cosmetics Rules, 1945.

\section{MATERIAL AND METHODS}

Package inserts accompanying allopathic medicines were obtained from a drug store and three pharmacies around a tertiary care centre in Western India on request over a 1-month period. The package inserts were included in the study and analysed for the presentation and completeness of information according to the headings mentioned in Section 6.2 and Section 6.3 of Schedule D, The Drugs and Cosmetics Rules, 1945.

\section{RESULTS}

110 package inserts were analysed in the study. None of the reviewed package insert contained all the sections as required by the Drugs and Cosmetic Rules.

\section{CONCLUSION}

To avoid medication errors due to deficits in drug information in package inserts, tighter monitoring of package inserts by regulatory authorities is recommended. Steps should be taken to ensure that the information in the package inserts follows a standard layout for easy and convenient comprehension.

\section{KEYWORDS}

Package Inserts, Drug Information, Schedule D, The Drugs and Cosmetics Rules.

HOW TO CITE THIS ARTICLE: Agharia MAM, Gawali UP, Kesari HV, et al. A critical appraisal of package inserts in India. J. Evolution Med. Dent. Sci. 2016;5(45):2785-2788, DOI: 10.14260/jemds/2016/650

\section{INTRODUCTION}

Accurate and reliable drug information is essential for safe and effective use of marketed drug products. The primary source of drug information is a Package Insert. It is a printed leaflet that contains information based on regulatory guidelines for the safe and effective use of a drug.[1]

The World Health Organization states that "Product information must help patients and other users to understand the medication.

Financial or Other, Competing Interest: None.

Submission 20-04-2016, Peer Review 13-05-2016,

Acceptance 20-05-2016, Published 03-06-2016.

Corresponding Author:

Dr. Agharia Makbool Ali M.

Room No. 114, Resident Doctors Hostel,

Dr. V. M. Government Medical College,

Solapur,

Maharashtra.

E-mail:makbool.ali@gmail.com

DOI: $10.14260 /$ jemds $/ 2016 / 650$
The patient package insert, together with the label, provides the patient with key information concerning the proper use of the product, potential adverse reactions and interactions, storage conditions and the expiry date."[2] Incomplete and incorrect product information may have serious consequences including disability or death. ${ }^{[3]}$

In India, the concept of package insert is governed by the Drugs and Cosmetics Act (1940) and Rules (1945). Section 6 of Schedule D (II) of the Rules, lists the headings according to which information should be provided in the package inserts. 'Section 6.2' mandates that the package insert must be in English and must include information on therapeutic indications; posology and method of administration; contraindications; special warnings and precautions; drug interactions; contraindications in pregnancy and lactation; effects on ability to drive and use machines; undesirable effects; and antidote for overdosing. 'Section 6.3' mandates pharmaceutical information on list of excipients; incompatibilities; shelf life as packaged, after dilution or reconstitution or after first opening the container; special 
precautions for storage; nature and specification of container; and instruction for use/handling. ${ }^{[4]}$ (see Table 1).

Currently in India, the structure and content of the information on the inserts appears to be geared towards prescribers only and the text in Schedule Y of the rules does refer to package inserts as prescribing information. ${ }^{[3]}$ Keeping this in mind, this study was designed to evaluate the presentation and completeness of drug information provided in the currently available package inserts for allopathic drugs in India.

\begin{tabular}{|c|c|}
\hline Section 6.2 & Section 6.3 \\
\hline Therapeutic Information & $\begin{array}{l}\text { Pharmaceutical } \\
\text { Information }\end{array}$ \\
\hline $\begin{array}{l}\text { Posology and method of } \\
\text { administration }\end{array}$ & List of excipients \\
\hline Contraindication & Incompatibilities \\
\hline $\begin{array}{l}\text { Special warning and } \\
\text { precaution }\end{array}$ & $\begin{array}{l}\text { Shelf life as package for } \\
\text { sale }\end{array}$ \\
\hline Interaction & $\begin{array}{l}\text { Shelf life after dilution or } \\
\text { reconstitution }\end{array}$ \\
\hline Pregnancy and lactation & $\begin{array}{l}\text { Shelf life after opening the } \\
\text { container }\end{array}$ \\
\hline $\begin{array}{l}\text { Effects on ability to drive, if } \\
\text { contraindicated }\end{array}$ & $\begin{array}{l}\text { Special precaution for } \\
\text { storage }\end{array}$ \\
\hline Undesirable effects & $\begin{array}{l}\text { Nature and specification of } \\
\text { container }\end{array}$ \\
\hline Antidote for overdosing & $\begin{array}{l}\text { Instruction for } \\
\text { use/handling }\end{array}$ \\
\hline \multicolumn{2}{|c|}{$\begin{array}{c}\text { Table 1: Schedule D of the Drugs and } \\
\text { Cosmetics Rules (1945) }\end{array}$} \\
\hline
\end{tabular}

\section{MATERIAL AND METHODS}

This study is a cross-sectional survey-based observational study. After approval from the Institutional Ethics Committee, package inserts accompanying allopathic medicines were obtained from a drug store and three pharmacies around a tertiary care centre in Western India on request over a 1month period. Duplicate package inserts were identified and excluded. The remaining package inserts were included in the study and analysed for the presentation and completeness of information according to the headings mentioned in Section 6.2 and Section 6.3 of Schedule D, The Drugs and Cosmetics Rules, 1945.

The package inserts were checked for the presence of each heading mentioned in Section 6.2 and Section 6.3 followed by careful scrutiny of information given under the heading. If a heading was found missing, the whole package insert was checked for pertaining information. If the information was found present it was scored one and zero if found absent. All package inserts were expected to contain information pertaining to the headings listed in the Drugs and Cosmetic Rules, or at least a disclaimer statement regarding the lack of such information.

After each of the selected package inserts was scored, the total score for each heading was calculated by totaling the scores from individual package inserts. The total score was expressed as absolute numbers and percentages. Additional headings if present in any package were recorded appropriately. The package inserts were also graded as poor, good or very good depending upon the total score of individual package inserts out of 16 .

\section{RESULTS}

A total of 119 package inserts were collected over the study period, out of which 9 were duplicate and hence were excluded from the study. The remaining 110 package inserts were used for analysis. The classification of drug package inserts according to the type of formulation is given in Figure 1. Analysis of data as per Section 6.2 and 6.3 is given in Table 2 . None of the reviewed package inserts contained all the sections as required by the Drugs and Cosmetics Rules, 1945. In total 16 headings were evaluated under Section 6.2 and 6.3, the highest score of package insert for presence of headings and pertaining information was 14 .

The structure of the package inserts was not uniform and it was difficult to retrieve the information due to lack of a common layout; posology and administration, contraindications, special precautions and warning were present in all the $(100 \%)$ package inserts. Adverse reactions were mentioned in $98.18 \%$ of the inserts. Drug interactions were mentioned in $83.63 \%$ of package inserts. Information about drug use in pregnancy and lactation was mentioned in $82.72 \%$ of package inserts. The information on effect on ability to drive and operate machines was mentioned in only $17.27 \%$ of package inserts; this was perhaps due to the fact that rest of the drugs did not have central nervous system activity. Information on antidote in case of overdose were present in $70 \%$ of package inserts.

The information under pharmaceutical section (Section 6.3) had many deficiencies. List of excipients were mentioned in $43.63 \%$, but very few (8\%) mentioned them under a separate heading, the rest mentioned them under composition of the drug. Incompatibilities were mentioned in $41.81 \%$ of package inserts. Shelf life as package, shelf life after reconstitution and shelf life after opening the package were mentioned in $48.18 \%, 20 \%$ and $17.27 \%$ of package inserts respectively, but these were not mentioned under separate headings in any of the inserts as required, most of them mentioned them under a common heading of shelf life. Nature and specification of container were mentioned in $86.36 \%$, while instruction for use/handling were mentioned in $40 \%$ of package inserts.

Grading of the package inserts into poor, good and very good after scoring the individual package inserts out of a total score of 16 showed that none of the package inserts were graded as poor (score $0-6$ ), most of the package inserts (88) were graded as good (score 7-12) and 22 package inserts were graded as very good (score 13-16). (See Figure 2) Additional information apart from Section 6.2 and Section 6.3 mentioned in the package inserts is shown in Table 2.

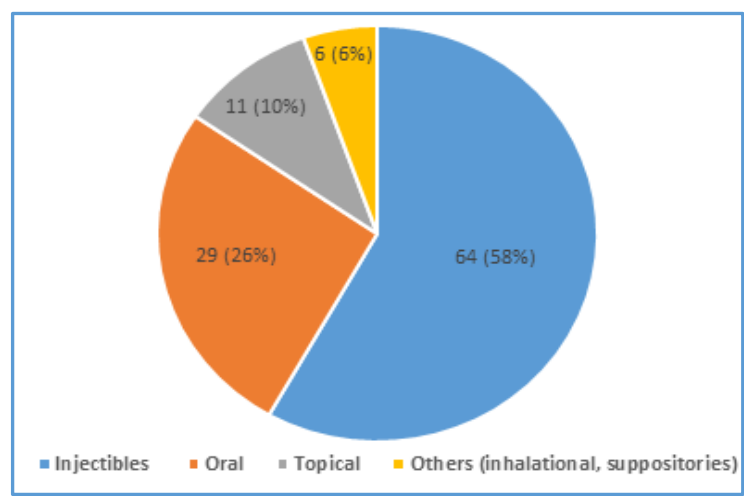

Fig. 1: Classification of Drug Package Inserts According to the Type of Formulation (Total Number =110) [n(\%)] 


\begin{tabular}{|c|c|c|c|}
\hline $\begin{array}{c}\text { Sr. } \\
\text { No. }\end{array}$ & Section 6.2 & $\begin{array}{c}\text { No. of } \\
\text { Package } \\
\text { Inserts }\end{array}$ & Percentage \\
\hline 1. & $\begin{array}{c}\text { Posology and method of } \\
\text { administration }\end{array}$ & 110 & $100 \%$ \\
\hline 2. & Contraindication & 110 & $100 \%$ \\
\hline 3. & $\begin{array}{c}\text { Special precautions and } \\
\text { warning }\end{array}$ & 110 & $100 \%$ \\
\hline 4. & Interaction & 92 & $83.63 \%$ \\
\hline 5. & $\begin{array}{c}\text { Pregnancy and lactation } \\
\text { if contraindicated }\end{array}$ & 91 & $82.72 \%$ \\
\hline 6. & $\begin{array}{c}\text { Effect on ability to drive } \\
\text { or operate machines }\end{array}$ & 19 & $17.27 \%$ \\
\hline 7. & $\begin{array}{c}\text { Undesirable effects/side } \\
\text { effects }\end{array}$ & 108 & $98.18 \%$ \\
\hline 8. & Antidote for overdose & 77 & $70 \%$ \\
\hline Sr. & Section 6.3 & $\begin{array}{c}\text { No. of } \\
\text { Insage }\end{array}$ & Percentage \\
\hline No. & Inserts & $43.63 \%$ \\
\hline 1. & List of excipients & 48 & $41.81 \%$ \\
\hline 11. & $\begin{array}{c}\text { Shelf life in the product } \\
\text { package for sale }\end{array}$ & 53 & $48.18 \%$ \\
\hline 12. & $\begin{array}{c}\text { Shelf life after } \\
\text { dilution/reconstitution } \\
\text { according to direction }\end{array}$ & 22 & $20 \%$ \\
\hline 13. & $\begin{array}{c}\text { Shelf life after opening } \\
\text { the container }\end{array}$ & 19 & $17.27 \%$ \\
\hline 14. & $\begin{array}{c}\text { Special precautions for } \\
\text { storage }\end{array}$ & 101 & $91.81 \%$ \\
\hline 15. & $\begin{array}{c}\text { Nature and specification } \\
\text { of container }\end{array}$ & 95 & $86.36 \%$ \\
\hline 16. & $\begin{array}{c}\text { Instruction for } \\
\text { use/handling }\end{array}$ & 44 & $40 \%$ \\
\hline Table 2: Result of Analysis of Drug Package Inserts \\
\hline
\end{tabular}

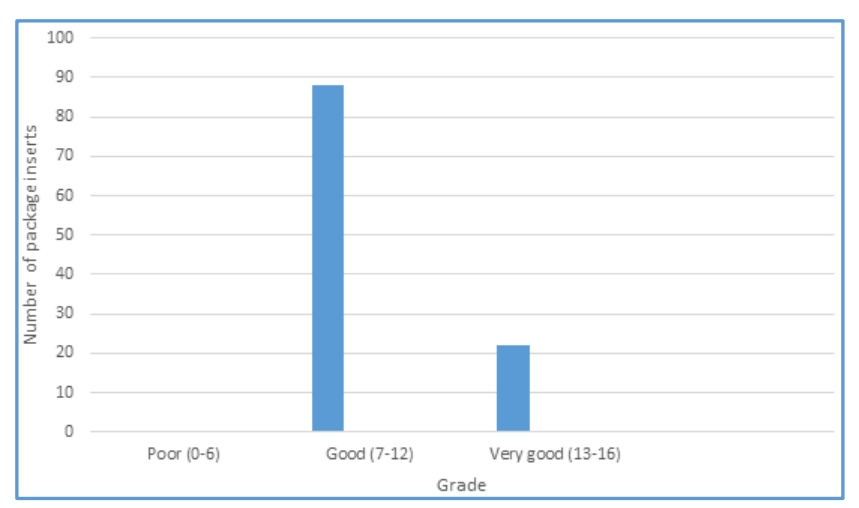

Fig. 2: Grading of the Drug Package Inserts (Total Number = 110)

\begin{tabular}{|c|c|c|}
\hline $\begin{array}{c}\text { Additional } \\
\text { Information }\end{array}$ & $\begin{array}{c}\text { No. of } \\
\text { Package } \\
\text { Inserts }\end{array}$ & Percentage \\
\hline Composition & 110 & $100 \%$ \\
\hline Drug description & 101 & $91.81 \%$ \\
\hline Indication & 110 & $100 \%$ \\
\hline $\begin{array}{c}\text { Clinical } \\
\text { Pharmacology/Mechanism of } \\
\text { action }\end{array}$ & 92 & $83.63 \%$ \\
\hline Pharmacokinetics & 68 & $61.81 \%$ \\
\hline
\end{tabular}

\section{DISCUSSION}

The safe and efficient use of drugs requires that accurate, complete, specific and timely information be disseminated to the prescribers and users in a readily comprehensible manner. Package insert is one such reliable source of information, which receives prior approval by the respective administrative authority and which if used effectively can be a reliable tool for the minimization of medication errors.[5]

This study showed that package inserts accompanying allopathic medicines in India are inadequate in many aspects. In this study we found that important information under Section 6.2 like posology and method of administration, contraindication, special precaution and undesirable/side effects warning was present in almost all the package inserts which is better than the studies reported by Shivkar.[3], Kalam et al[6] and Solanki et al.[7] Vital information like interactions, pregnancy and lactation if contraindicated was present in $83.63 \%$ and $82.72 \%$ respectively, which is similar to the study reported by Shivkar and Sudhamadhuri et al[8], but slightly lower when compared to the study reported by Kalam et al. Information on effect on ability to drive and over-dosage was present in $17.27 \%$ and $70 \%$ respectively, which is better than the study reported by Kalam et al.

The pharmaceutical information was not appropriate in the package inserts analysed. The information provided had lot of deficiencies. Information on excipients was provided in only $43.63 \%$ of the package inserts which is similar to the study reported by Sudhamadhuri et al, but lower when compared to Kalam et al, Solanki et al and Soumya et al.[9] Only $8 \%$ mentioned this information under a clear separate heading. Shelf life of the product for sale after dilution or reconstitution and after first opening the container also had grave pitfalls.

Though this information was better represented as compared to the studies reported by Kalam et al, Solanki et al, Sudhamadhuri et al and Soumya et al, it was mentioned under a common heading. Instructions for the use/handling of the products were given in only $40 \%$ of the package inserts, which is similar to the studies reported by Soumya et al and Ramdas et al[1], but better than the one reported by Kalam et al. This information is of importance to help patients use the medication effectively, e.g. inhalers for asthma. Information on storage, nature and specification of container was fairly mentioned in $91.81 \%$ and $86.36 \%$ of package inserts respectively, which is better than the studies reported earlier.

None of the package inserts had all the headings of information as required by Section 6.2 and 6.3 of Drug and Cosmetics Rule (1945). The highest score for package inserts out of a maximum of 16 was 14, which was present in just 6 $(6 \%)$ package inserts. It was however noted that there has been an overall improvement in the quality and content of package inserts when compared to earlier studies and none of the package inserts were graded as poor (Score less than 7).

\section{CONCLUSION}

This study shows that though there has been a modest improvement in presentation and completeness of information in drug package inserts, the information provided is still incomplete as per regulatory guidelines. To avoid medication errors due to deficits in drug information in package inserts, tighter monitoring of package inserts by regulatory authorities is recommended. Steps should be taken 
to ensure that the information in the package inserts follows a standard layout for easy and convenient comprehension. The regulatory authorities in India could strengthen collaboration and information interchange with international agencies to maintain quality standards for delivering information through these package inserts. The availability of a comprehensive database for the DCGI - approved package inserts in India would be of much help in this direction. Medication compliance can be improved by improving the awareness of patients about their medications. Also, there is a need for 'Patient-oriented Package Inserts' in India.[10]

\section{REFERENCES}

1. Ramdas D, Chakraborty A, Hs S, et al. A study of package inserts in southern India. J Clin Diagn Res 2013;7(11):2475-7.

2. Annex 9. Guidelines on packaging for pharmaceutical products, WHO technical report series, 2002;902. http://www.who.int/medicines/areas/quality_safety/q uality_assurance/GuidelinesPackagingPharmaceuticalP roductsTRS902Annex9.pdf.

3. Shivkar YM. Clinical information in drug package inserts in India. J Postgrad Med 2009;55(2):104-7.
4. Govt of India, Ministry of health and family welfare. Drug and Cosmetic Rules 1945;p 265. http://cdso.nic.in/html/Drugs and Cosmetic act.pdf

5. Ved JK. Package inserts in India: need for a revision. International Journal of Pharma sciences and Research 2010;1(11):454-6.

6. Kalam A, Anwar S, Fatima A. Drug package inserts in India: current scenario. World Journal of Pharmacy \& Pharmaceutical Sciences 2014;3(4):385-92.

7. Solanki SN, Chhaiya SB, Mehta DS, et al. Analytical evaluation of drug package inserts in India. Int J Basic Clin Pharmacol 2015;4(2):322-4.

8. Sudhamadhuri A, Kalasker V. Evaluation of completeness of package inserts in south India. International Journal of Research Studies in Biosciences 2015;3(7):102-5.

9. Sowmya B, Vijayalakshmi, Reddy SN. Critical appraisal of patient package inserts in allopathic medicines. Journal of Chemical and Pharmaceutical Research 2015;7(3):1805-8.

10. Patel SV, Desai CK, Patel PP, et al. An evaluation of package inserts of antimicrobial agents marketed in India. Int J Pharm 2015;5(1):158-64. 